\title{
DUElPC/89869-.T8
}

\section{Development of a Stable Cobait-Ruthenium Fischer-Tropsch Catalyst}

Contract DE-AC22-89PC89869

Hayim Abrevaya

UOP

25 E. Algonquin Road

DE92 041283

Des Plaines, Illinois

Technical Progress Report Na. 9

$(10 / 01 / 91 \cdot 12 / 31 / 91)$

\section{Contrast objective}

The objective of this contract is to examine the relationship between catalytic properties and the function of cobalt Fischer.Tropsch catalysts and to apply this fundamental knowledge to the development of a stable cobalt-based catalyst with a low methane-plus-ethane selectivity for use in slurry reactors.

\section{Contract Tasks}

Task 1.0: Project Management Report

Task 2.0: Reference Cobalt Catalyst

Task 3.1: Modifier Role for Ruthenium

Task 3.2: Particle Size Effects with Ruthenium

Task 4.1: Identification of the Synergy between Cobalt and a Second Bimetallic Element, such as Ruthenium

Task 4.2: Development of a Bimetallic Catalyst

Task 5.0: Demonstration of Stability

\section{Scope of the Work during the Reporting Period}

A test procedure for screening cobalt catalysts in the fixed-bed reactor was developed during the previous quarter.' In that work, three different support materials (Nos. 8 to 10) and two promoters (Nos. 2 and 3) were evaluated. During this reporting period, support No. 8 was tested again by the application of an alternative preparation procedure; also, a new support (No. 11) was PATENT CLEARED BY CHICAGO 
evaluated. As in the work reported during the previous quarter, all cobalt catalysts contained the bimetallic component 1. Promising catalysts identified by the fixed-bed rapid-screening procedure will be further evaluated in the slurry-autoclave reactor.

\section{Experimental}

The fixed-bed pilot plant, the catalyst testing procedure, and the calculations for conversion and selectivities were previously described.' Table 1 summarizes the following information for each run: the catalyst identification, the nature of diluent, the catalyst and diluent weights, the mesh-size range for the diluent, the catalyst inlet temperature ( 2 inches before the catalyst bed), the catalyst maximum temperature, the reactor outlet pressure, the composition of the feed, the feed rate, and the space velocity.

\section{Results and Discussion}

\section{Run 68}

Catalyst 585R2775 (cobalt and bimetallic component 1 on support No. 11) had 5.10 nm crystallites, according to scanning transmission electron microscope (STEM) examination. The STEM examination also indicated that the bimetallic component was not incorporated into the crystallites.

At $210^{\circ} \mathrm{C}, 21 \mathrm{~atm}, 4.8 \mathrm{NL} / \mathrm{hr} / \mathrm{gCo}$ space velocity and $\mathrm{H}_{2}: \mathrm{CO}$ feed ratio of $2: 1$, the initial $\mathrm{CO}+\mathrm{H}_{2}$ conversion was $48 \%$ in Run 68 (Figure 1). A rapid deactivation to about 20\% conversion was then observed in 10 hours. Under these condirions, the selectivity to methane varied between 26 and $19 \%$ (Figure 2). This catalyst also made a large amount of ethane and other light gases (Figures 3 to 5). The selectivity to methane, ethane, and other light gases increased at $230^{\circ} \mathrm{C}$. The $10 \mathrm{w} \mathrm{CO}_{2}$ selectivity illustrates that this catalyst was not active for the water-gas shift reaction.

The catalyst performance observed in Run 68 was significantly inferior to that observed in Run 67 with bimetallic cobalt cataly'st prepared on Support No. 10 (Catalyst 585R2796). ${ }^{1}$ As a 
result of this work, support No. 11 will not be considered for cobalt impregnation in the future work.

\section{Run 69}

According to STEM, catalyst 585R2810 (cobalt and bimetallic component 1 on support No. 8) consists of 5 to $35 \mathrm{~nm}$ crystallites, the bulk of which are 10 to $20 \mathrm{~nm}$ in size. The fact that the bimetallic component was not fully incorporated into the crystallites suggests that some of it may be on the support.

Catalyst $585 \mathrm{R} 2810$ initially showed $35 \% \mathrm{CO}+\mathrm{H}_{2}$ conversion at $210^{\circ} \mathrm{C}, 21$ atm, 4.8 $\mathrm{NL} / \mathrm{hr} / \mathrm{gCo}$, and a $\mathrm{H}_{2}: \mathrm{CO}$ feed ratio of $2: 1$ (Run 69, Figure 7). Following deactivation, the conversion lined-out at about the $10 \%$ level. At 30 hours, the temperature was increased to $230^{\circ} \mathrm{C}$ and caused the conversion to increase to about 37\%. The catalyst continued to deactivate at $230^{\circ} \mathrm{C}$ (Figure 7). At 60 hours, the space velocity was decreased to $2.4 \mathrm{NL} / \mathrm{hr} / \mathrm{gCo}$. The $\mathrm{CO}+$ $\mathrm{H}_{2}$ conversion reached a peak of $59 \%$ at 72 hours on-stream and continued to deactivate.

At $210^{\circ} \mathrm{C}$, the methane selectivity was initially high and then decreased to about $10 \%$ (Figure 8). Following the condition change at 30 hours, the methane selectivity first increased to about $14 \%$ because of the increase in temperature and then started to decrease, probably because of the increase in the conversion level. At $230^{\circ} \mathrm{C}$ and 50 to $55 \% \mathrm{CO}+\mathrm{H}_{2}$ conversion, the methane selectivity was 10 to $11 \%$.

Other results, such as selectivities to ethane, ethylene, propane, propylene, butane, butylene, $\mathrm{C}_{1} \cdot \mathrm{C}_{4}$ alcohols and aldehydes, and $\mathrm{CO}_{2}$ as well as the usage ratio, are plotted as a function of time in Figures 9 to 13.

The methane selectivity observed in Run 69 is lower than the methane selectivities observed in Runs 62 and 66 with the earlier preparations on support No. 8.' These earlier preparations had 2 to $4 \mathrm{~nm}$ crystallites, and these crystallites had the bimetallic component incorporated. The results suggest that the crystallite size and composition influenced the catalytic selectivity. 
The selectivity observed in Run 69 is also superior to selectivities observed in Run 67 with the bimetallic cobalt catalyst prepared on support No. 10 . However, the bimetallic cobalt catalyst prepared on support No. 10 was much more active relative to the catalysts prepared on support No. 8.

\section{Conclusions}

The work performed in the program suggests that cobalt catalytic performance is a complex function of crystallite size, crystallite composition, and cobalt-support interaction. These properties are determined by the nature of support, the bimetallic component, the promoters, and the method of preparation. Results so far indicate that the lowest methane selectivity occurs on support No. 8, and the highest activity is obtained on support No. 10. Also, promoters 2 and 3 may help lower the formation of methane. These findings, along with the catalyst knowledge gained during Union Carbide's former contract DE.AC22-84PC70028, will be used to develop a superior cobalt catalyst.

\section{References}

1. Technical Progress Report No. 7 and 8 for 4/01/91 - 9/30/92, Contract DE-AC22-89PC89869, UOP, Des Plaines, Illinois. 


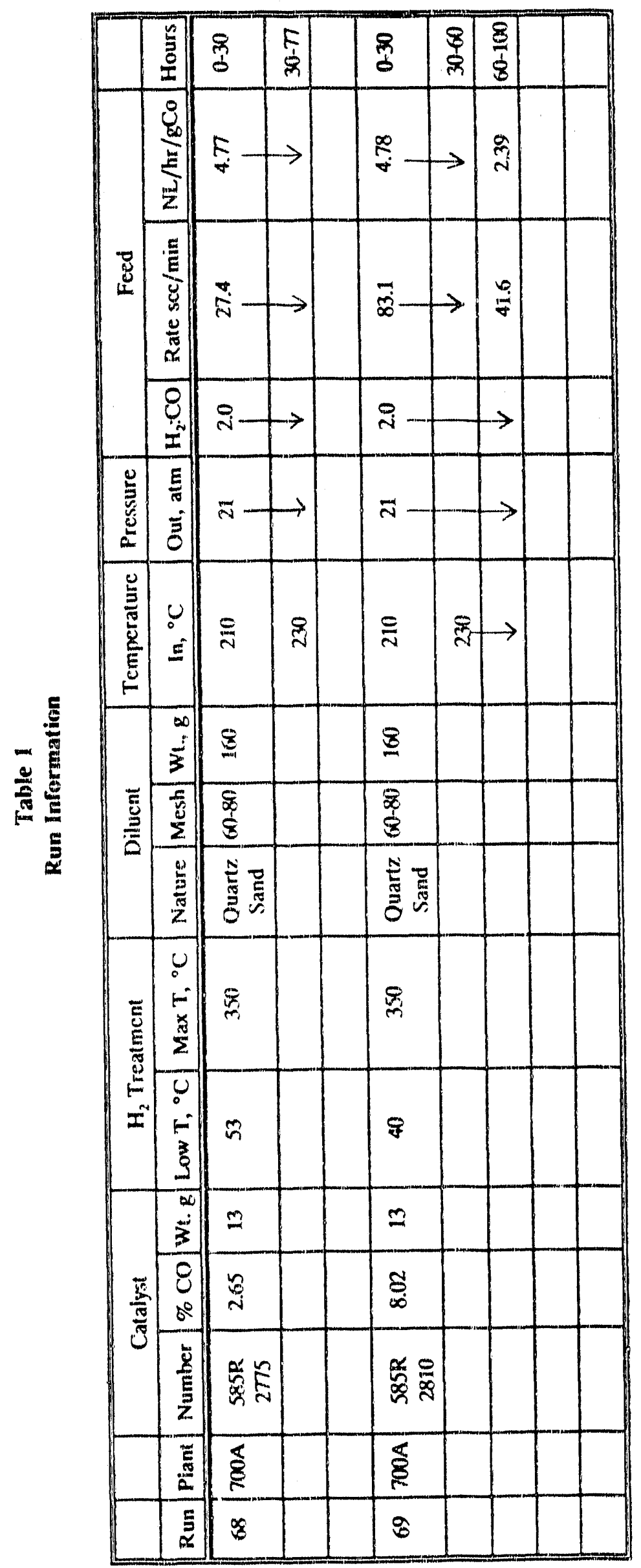


FIGURE 1: COBALT CATALYST 585R2775
PLT 700A RUN $68 \mathrm{H}_{2}:$ CO (MOLAR) $=2.0$
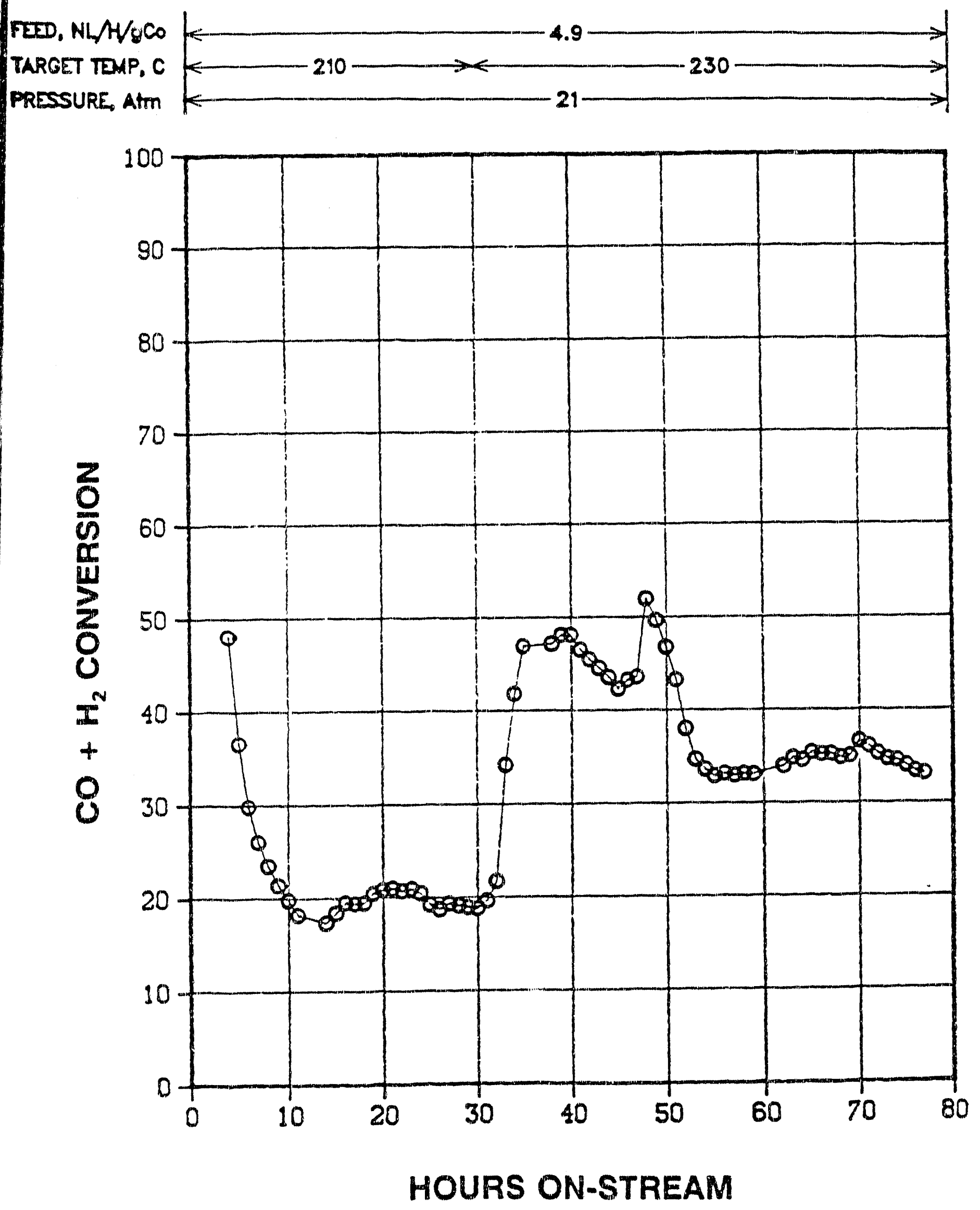
FIGURE 2: COBALT CATALYST 585R2775 PLT 70OA RUN $68 \mathrm{H}_{2}: \mathrm{CO}$ (MOLAR $=2.0$ )
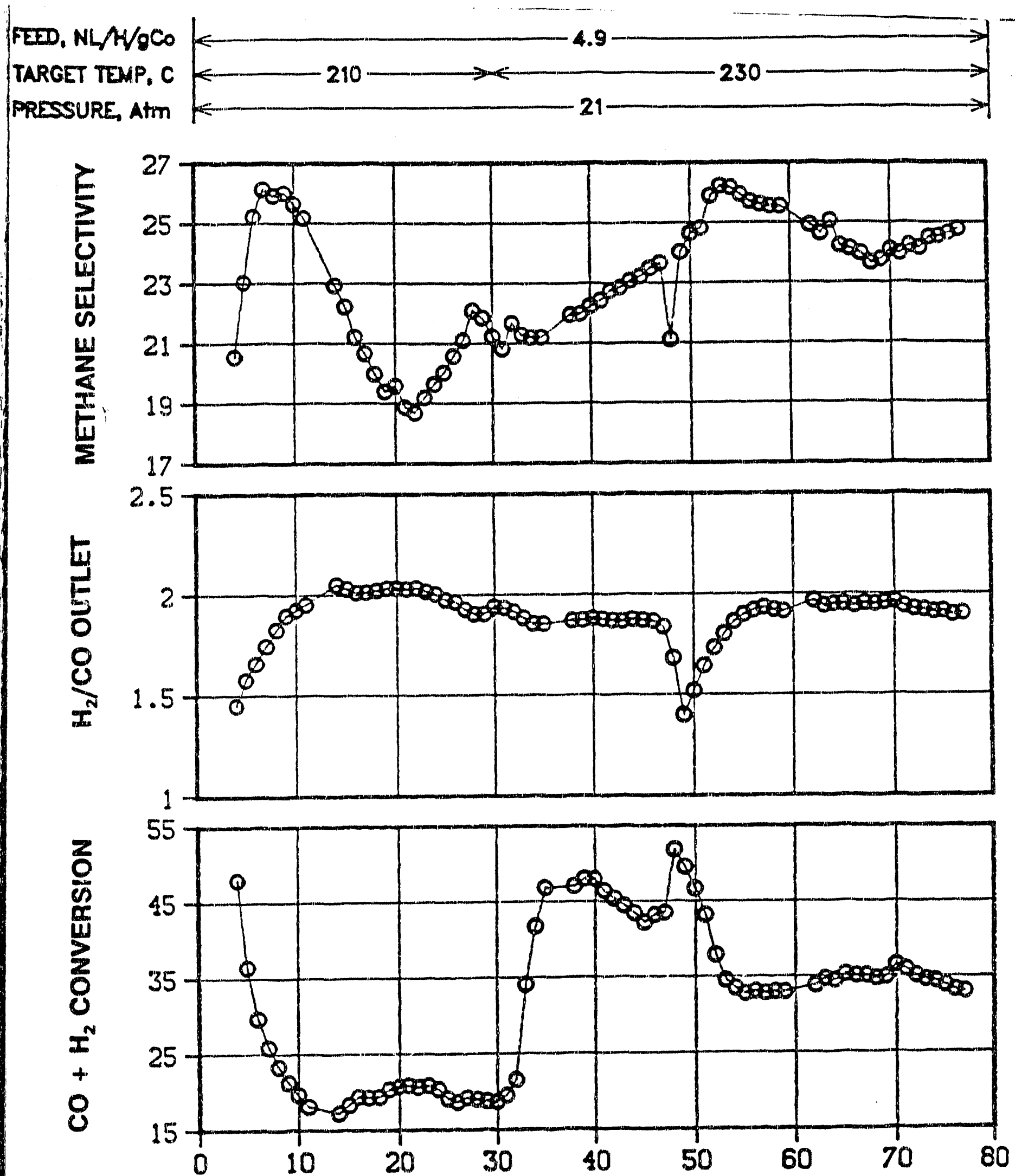


\section{FIGURE 3: COBALT CATALYST 585R2775 PLT 70OA RUN $68 \mathrm{H}_{2}$ :CO (MOLAR $=2.0$ )}
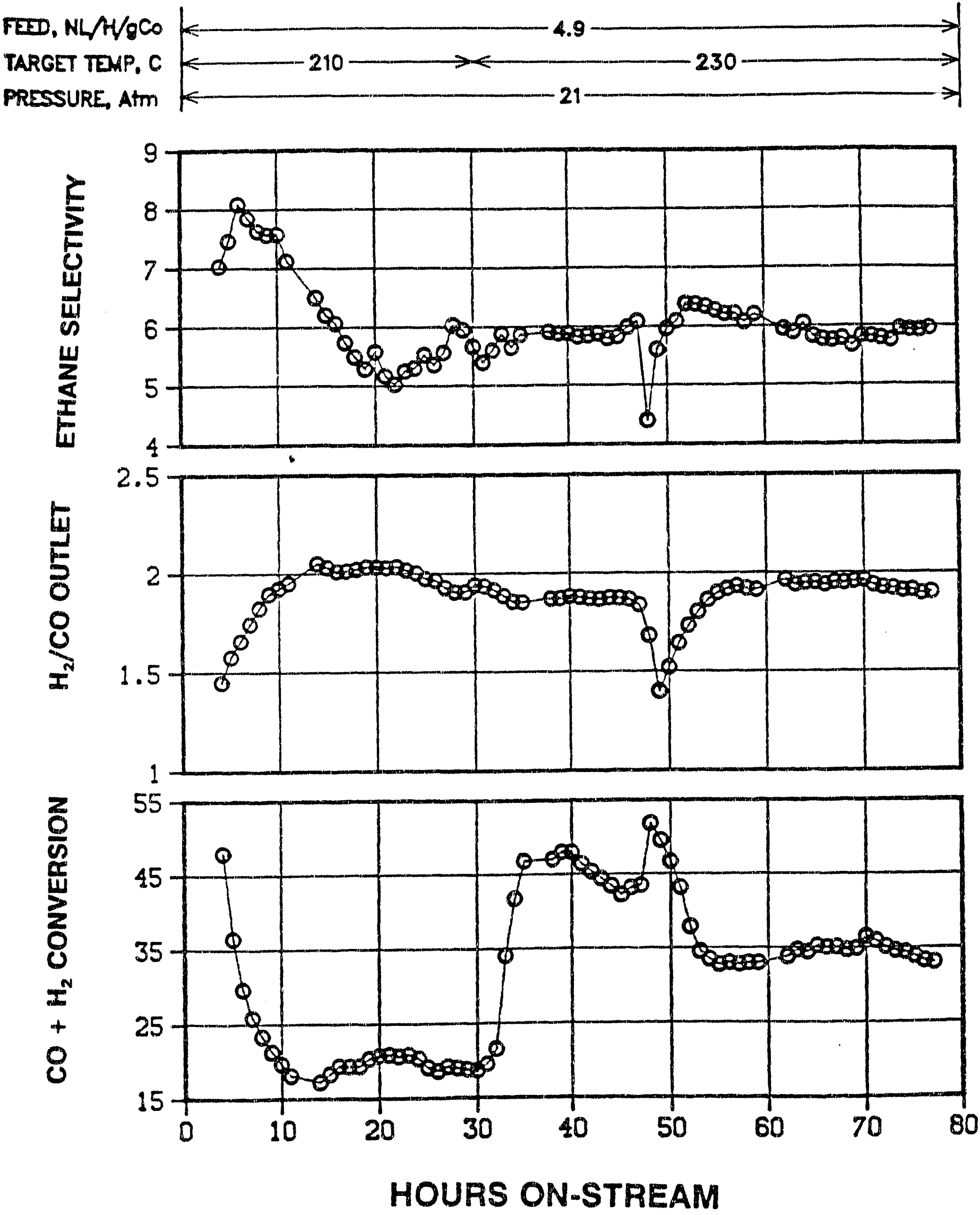


\section{FIGURE 4: COBALT CATALYST 585R2775 PLT 70OA RUN $8 B \mathrm{H}_{2}: \mathrm{CO}$ (MOLAR $=2.0$ )}

FEDD, NLAY/gCO
TARGET TEMP, C
PRESSURE, ATM

FIGURE 5: COBALT CATALYST 585R2775

PLT 700A RUN $68 \mathrm{H}_{2}: \mathrm{CO}$ (MOLAR $=2.0$ )
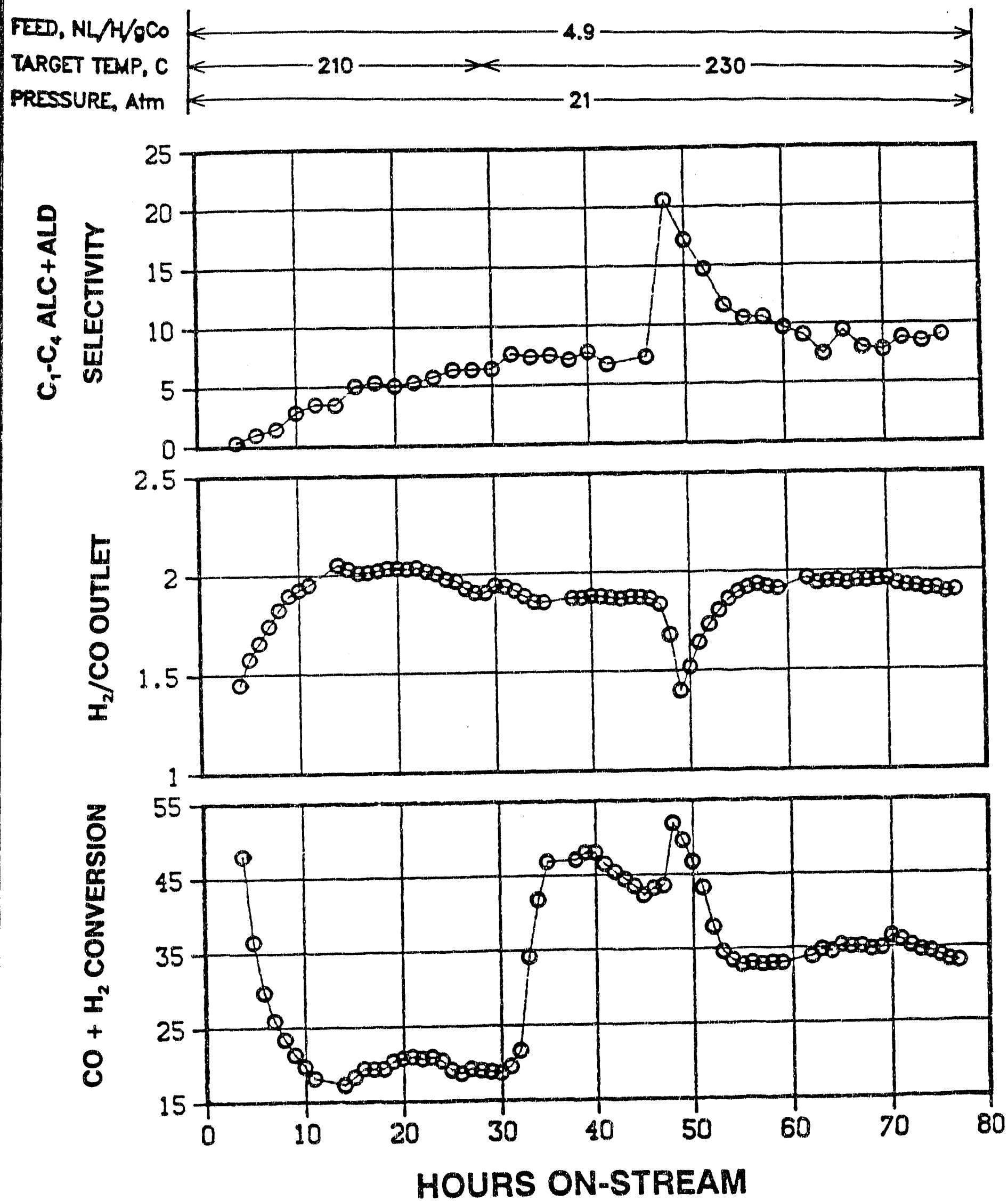
FIGURE 6: COBALT CATALYST 585R2775 PLT 700A RUN $68 \mathrm{H}_{2}: \mathrm{CO}$ (MOLAR $=2.0$ )

FEDD. NLAV/gCO

TARGET TEMP, C

PRESSURE, ATm $k$

4.9

$>$

210

21

230

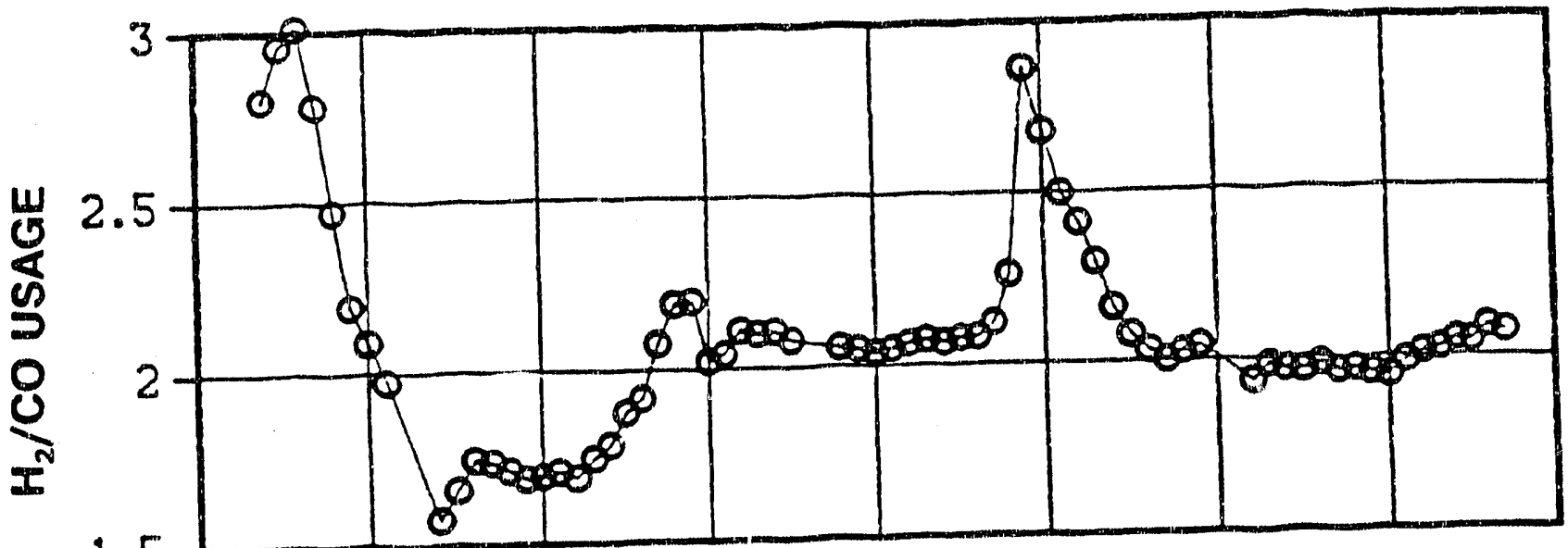

$$
1.5
$$

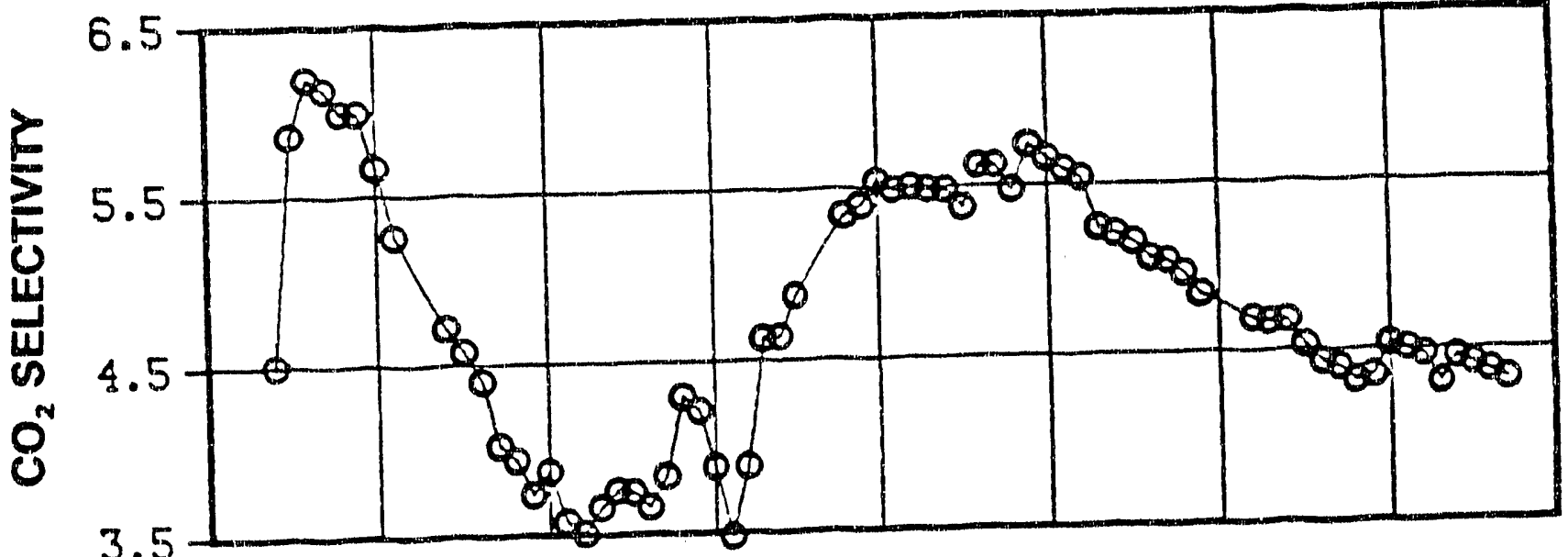

을

3.5

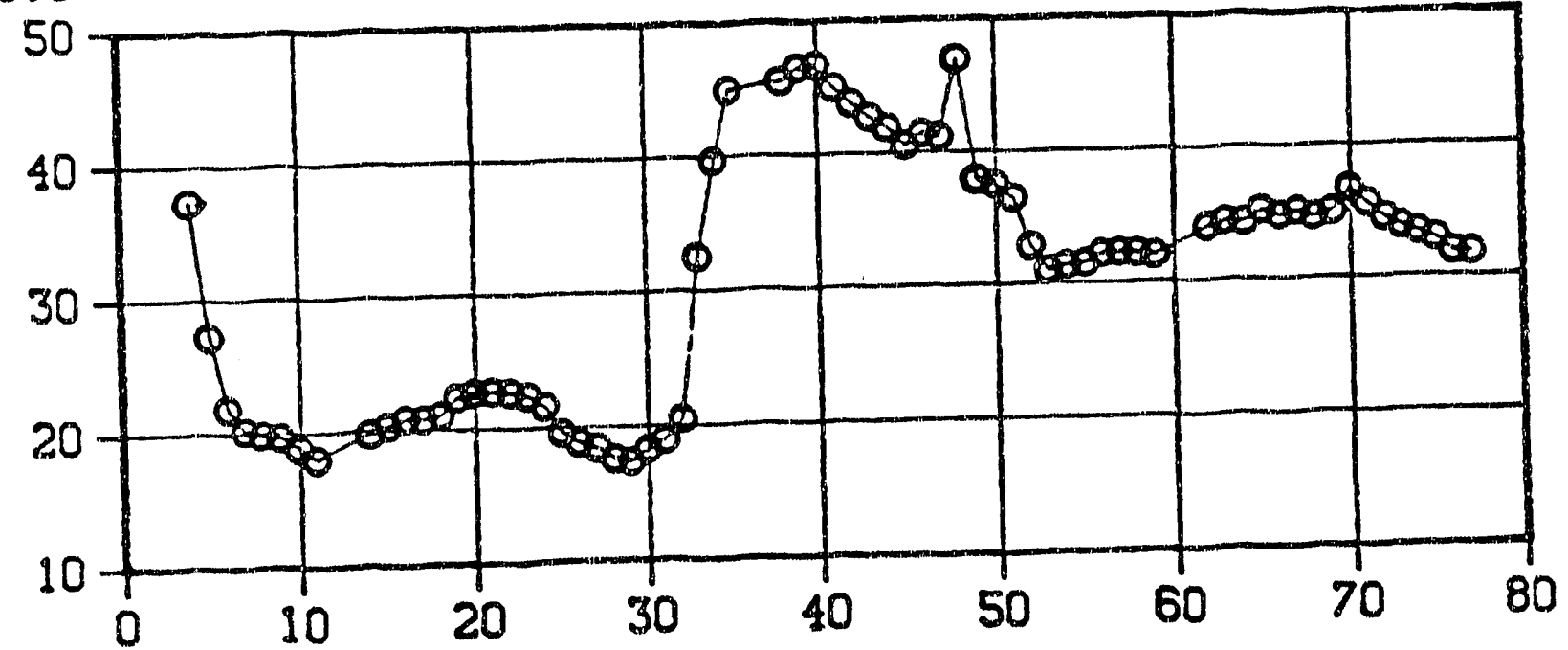

HOURS ON-STREAM 


\section{FIGURE 7: COBALT CATALYST 585R2775 PLT 700A RUN $69 \mathrm{H}_{2}$ :CO (MOLAR $=2.0$ )}
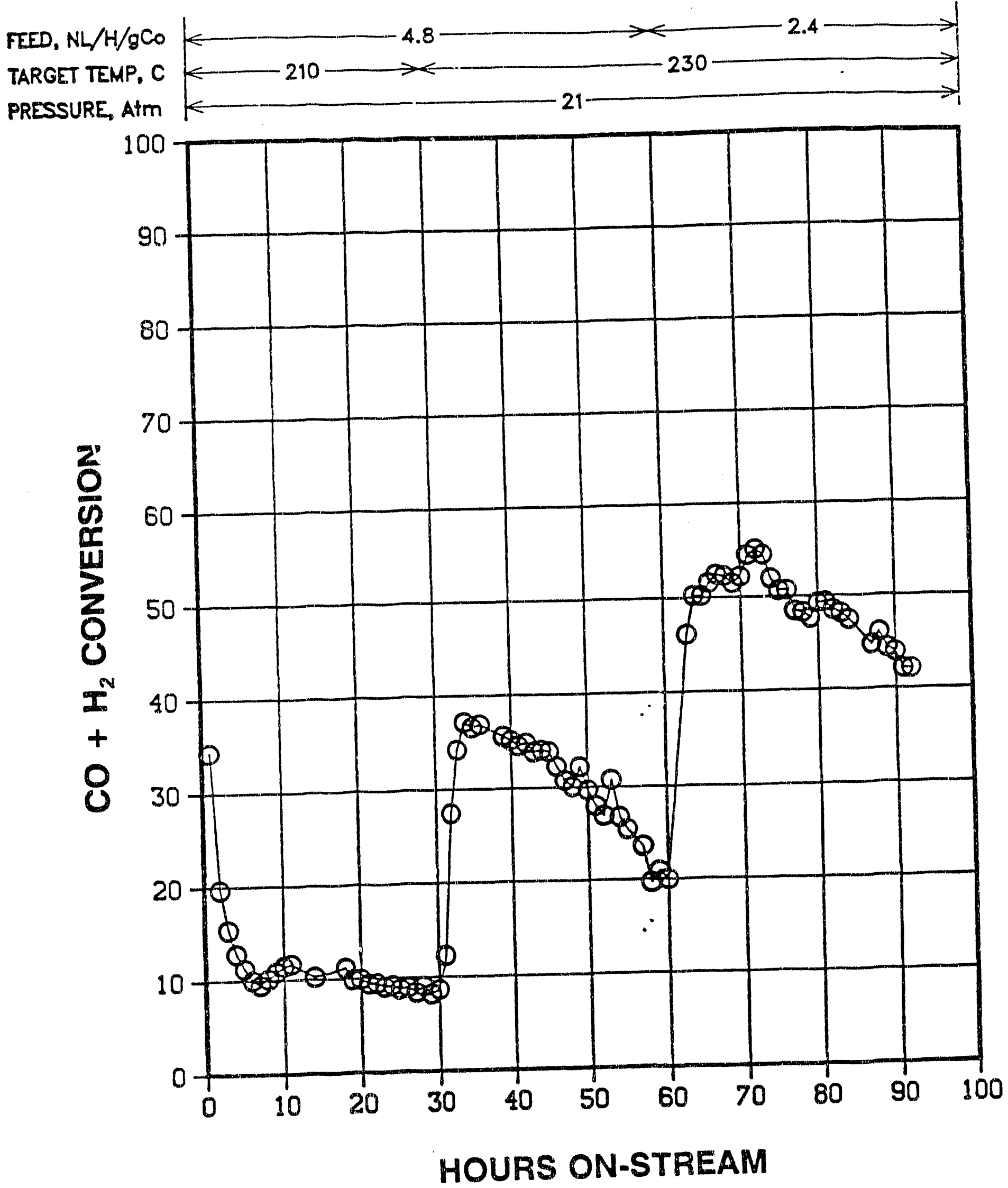


\section{FIGURE 8: COBALT CATALYST 585R2810 PLT 70OA RUN $69 \mathrm{H}_{2}$ :CO (MOLAR $=2.0$ )}

FEED, NL/H/gCO TARGET TEMP, $C$ PRESSURE, Atm

FIGURE 9: COBALT CATALYST 585R2810 PLT 700A RUN $69 \mathrm{H}_{2}: \mathrm{CO}$ (MOLAR $=2.0$ )

FIGURE 10: COBALT CATALYST 585R2810
PLT 700A RUN $69 \mathrm{H}_{2}:$ CO (MOLAR $\left.=2.0\right)$
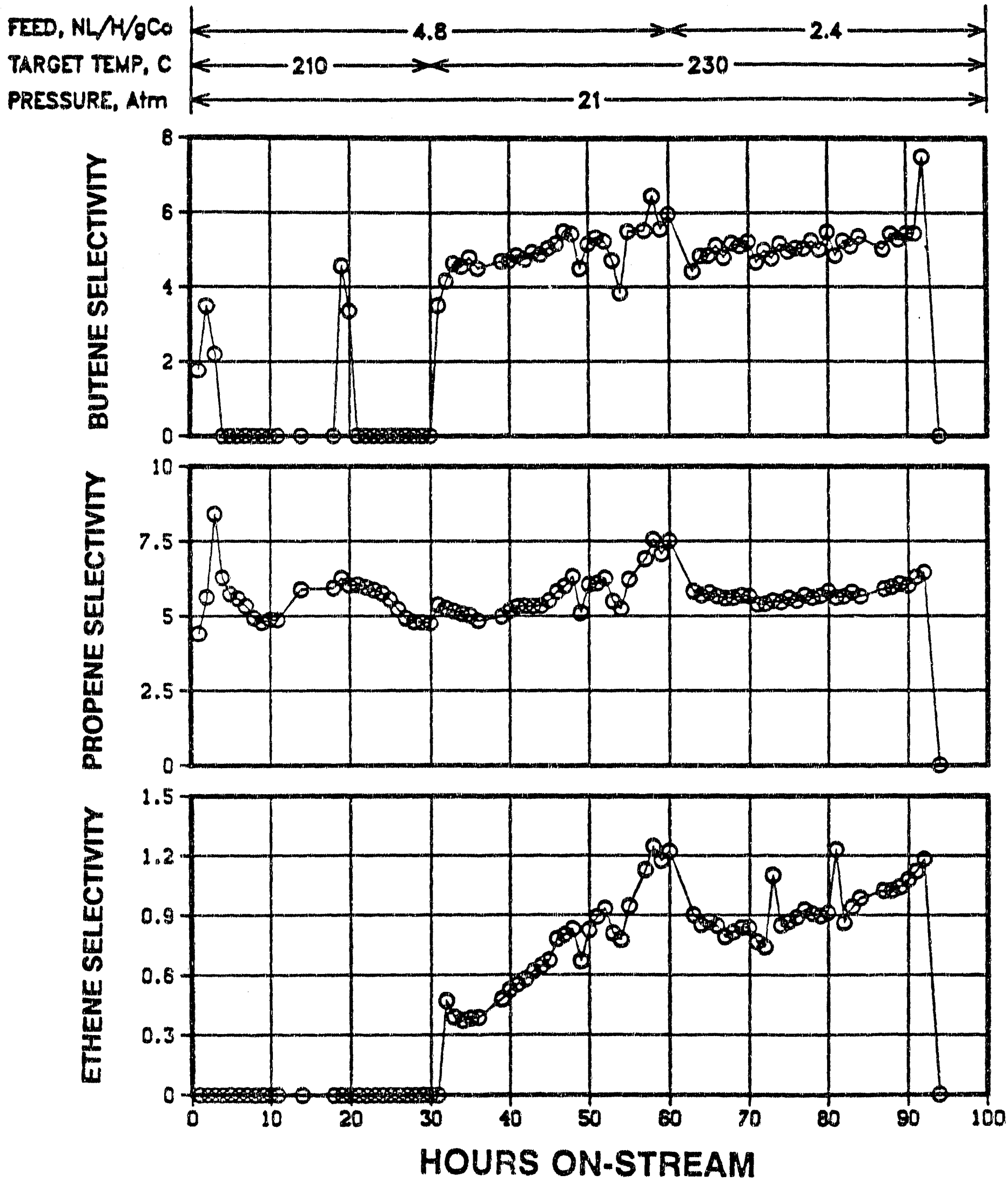


\section{FIGURE 11: COBALT CATALYST 585R2810 PLT 700A RUN $69 \mathrm{H}_{2}: \mathrm{CO}$ (MOLAR $=2.0$ )}



PRESSURE, ATI F
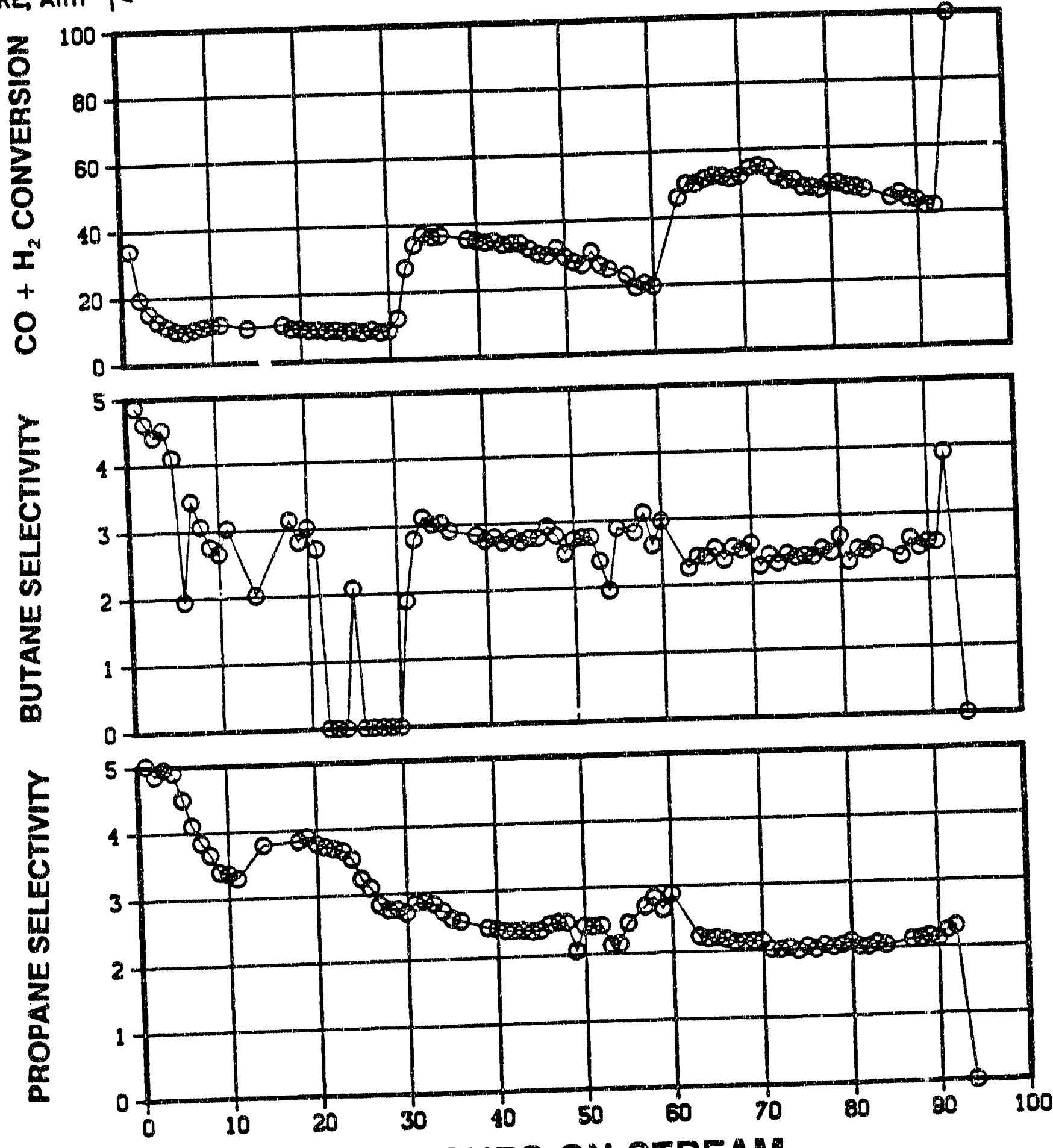

HOURS ON-STREAM 
FIGURE 12: COBALT CATALYST 585R2810 PLT 700A RUN $69 \mathrm{H}_{2}: \mathrm{CO}$ (MOLAR $=2.0$ )
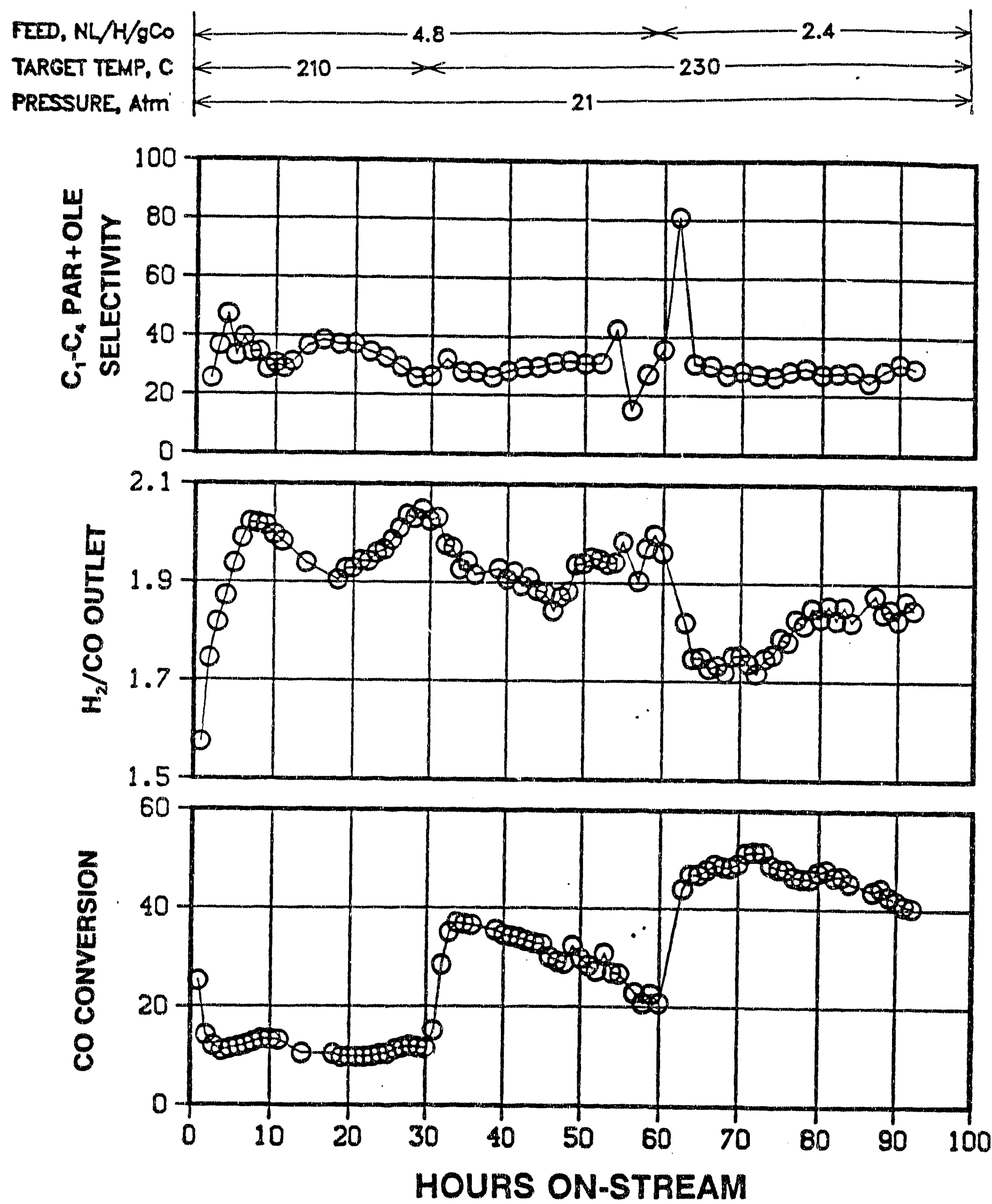


\section{FIGURE 13: COBALT CATALYST 585R2810 PLT 700A RUN $69 \mathrm{H}_{2}:$ CO (MOLAR $=2.0$ )}

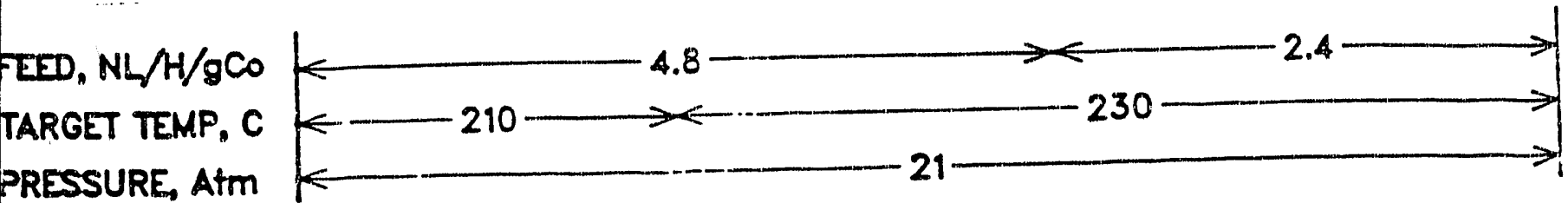
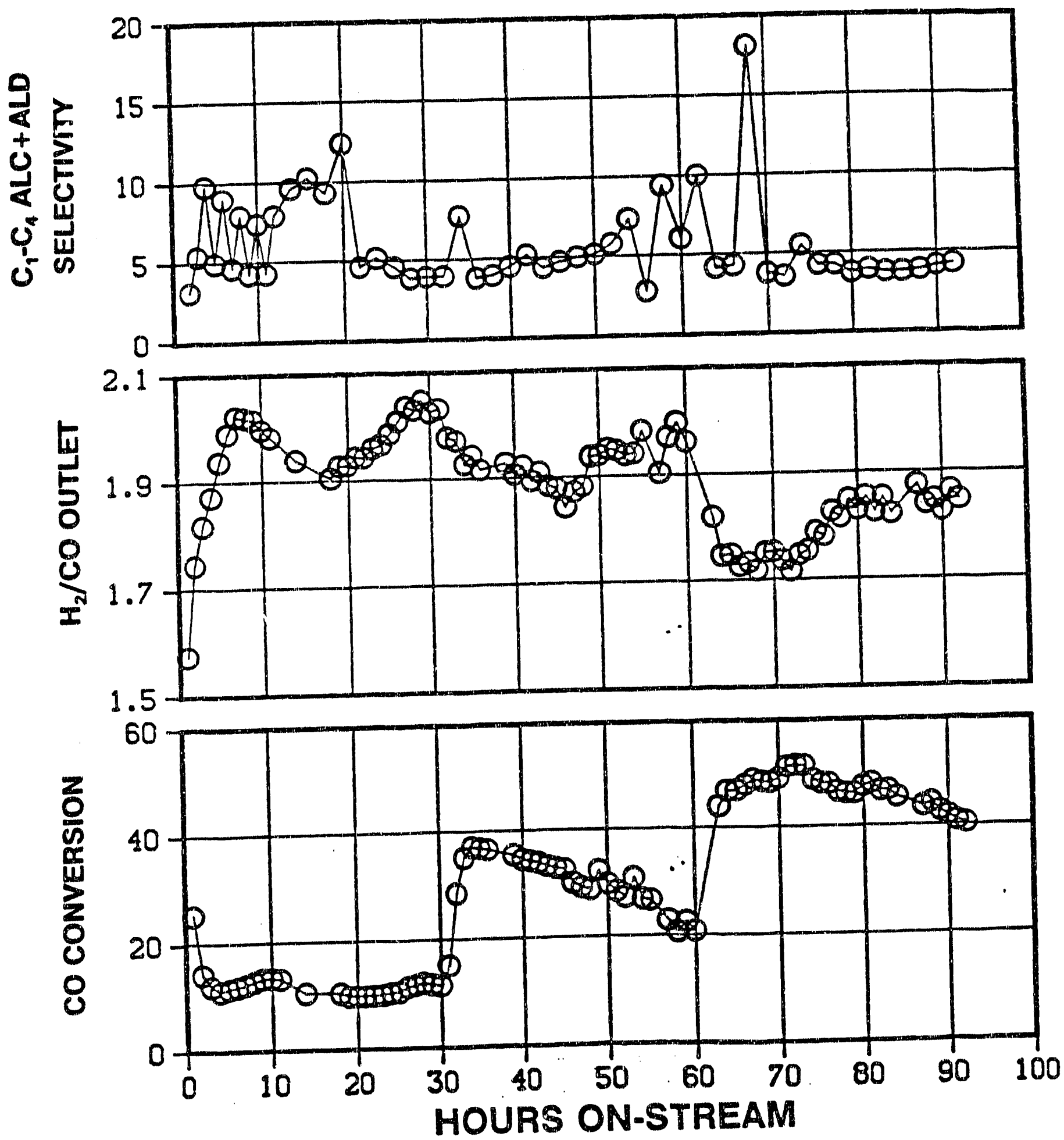


\section{FIGURE 14: COBALT CATALYST 585R2810 PLT 70OA RUN $69 \mathrm{H}_{2}$ :CO (MOLAR $=2.0$ )}


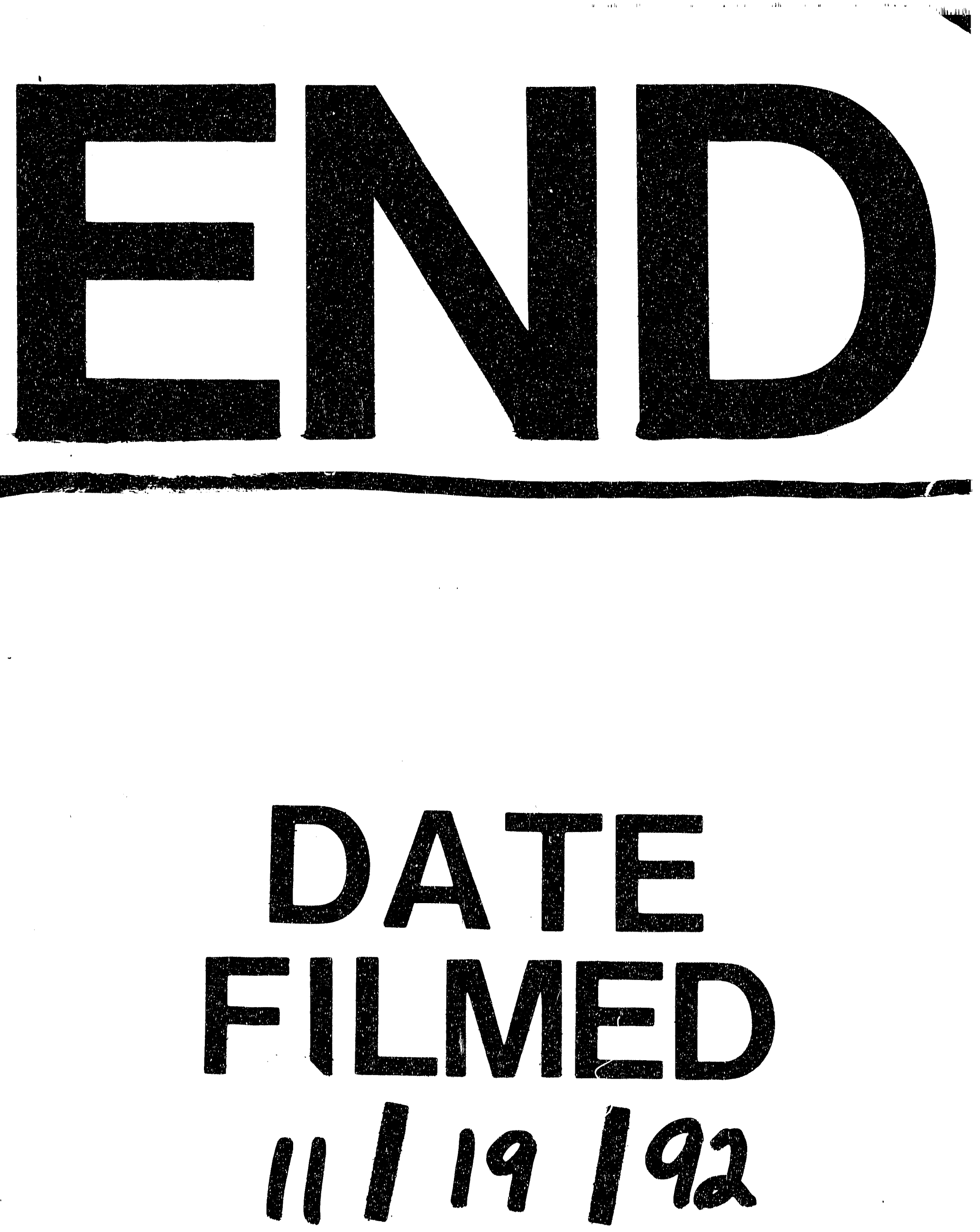
